\title{
Isolasi Dan Identifikasi Senyawa Kimia Monoterpen Dari Fraksi Etilasetat Daun Keji Beling (Strobilanthes crispa (L.) Blume) Yang Mempunyai Daya Sitotoksik
}

\author{
Lilik Sulastri ${ }^{*}$, Ristanti Mega Lestari ${ }^{1}$, Partomuan Simanjuntak ${ }^{2,3}$ \\ ${ }^{1}$ Sekolah Tinggi Teknologi Industri dan Farmasi (STTIF), Bogor \\ ${ }^{2}$ Puslit Kimia, Lembaga Ilmu Pengetahua Indonesia (LIPI), Serpong, Tangerang Selatan \\ ${ }^{3}$ Fakultas Farmasi, Universitas Pancasila, Jakarta
}

\begin{tabular}{|c|c|}
\hline Article info & Abstract \\
\hline History & Isolation and identification one of chemical compound mono-terpene from \\
\hline Submission: $23-10-2020$ & Keji beling plant (local name) (Strobilanthes crispa) has been done. \\
\hline Review: 07-12-2020 & Extraction was carried out by maceration of the keji beling leaf powder with \\
\hline Accepted: 19-01-2021 & ethanol $96 \%$, then partitioned with water-ethyl acetate. Ethylacetate extract \\
\hline "Email: & $\begin{array}{l}\text { was isolated and purified by a cytotoxic guide fractionation system with } \\
\text { Brine Shrimp Lethality Test (BSLT) on column chromatography }\left(\mathrm{SiO}_{2} ; n \text { - }\right.\end{array}$ \\
\hline liliksulastri28@gmail.com & hexane - ethylacetate $=20: 1) ;$ and preparative Thin Layer \\
\hline DOI: $10.33096 /$ jffi.v8i1.721 & $\begin{array}{l}\text { Chromatography }(\mathrm{TLC})\left(\mathrm{SiO}_{2} ; \text {; } \text {-hexane - ethylaseate }=10: 1\right) \text { which gave } \\
\text { one compound in oily form. Based on identification by infra red spectra }\end{array}$ \\
\hline $\begin{array}{l}\text { Keywords: } \\
\text { D-limonene; } n\end{array}$ & $\begin{array}{l}\text { and gas chromatography-mass spectra }(G C-M S) \text {, the compound is a } \\
\text { monoterpene D-limone which has a cytotoxic power of } 73,11 \text { ppm. }\end{array}$ \\
\hline
\end{tabular}

Beling; Strobilanthus crispa (L.)

Blume; cytotoxic

\section{Pendahuluan}

Keji beling dengan nama Latin Strobilanthus crispa (L). Blume atau Sericocalyx crispus (L.) dapat tumbuh di tanah yang memiliki ketinggian 1-1000 m di atas permukaan laut. (Setyawan et al., 2016).

Secara tradisional tanaman ini banyak dimanfaatkan dalam pengobatan berbagai penyakit. Sebuah survei obat herbal di melayu pemukiman Gemencheh bagian negri Sembilan, Malaysia mengungkapkan penerapan $S$. crispa digunakan untuk mengobati batu ginjal dengan cara daun dipanaskan lalu diletakan di pinggul. Keji beling ini secara tradisional juga digunakan sebagai antidiabetes, laxative dan agen diuretic (Nurraihana and Norfarizan-Hanoon, 2013).

Berdasarkan beberapa penelitian yang telah dilakukan bahwa ekstrak etanol daun keji beling dapat meluruhkan batu ginjal karena memiliki aktivitas sebagai diuretik kuat. Selain itu juga daun keji beling juga memiliki manfaat sebagai antidiabetes, antikanker, antioksidan, diuretik dan laxative (Rahmat et al., 2006; Dali et al., 2017; Koh et al., 2017).

Aktivitas sitotoksik dalam suatu senyawa dapat diuji baik secara in vitro maupun in vivo. Beberapa di antara uji in vitro untuk mengetahui aktivitas sitotoksik adalah uji secara selular menggunakan sel kanker manusia yang diinduksi pada sel hewan. Cara tersebut cukup sulit dilakukan karena membutuhkan tempat dan peralatan tertentu serta perlu dilakukan oleh orang yang cukup terlatih (Meyer, Ferrigni and Putnam, 1982)(Clarkson et al., 2004). Karena itu, diperlukan uji awal yang lebih mudah dan sederhana yaitu dengan uji toksisitas metode Brine Shrimp Lethality Test (BSLT) menggunakan larva udang Artemia salina (R. Hamidi, Jovanova and Kadifkova Panovska, 2014).

Salah satu tanaman yang berpotensi sebagai antioksidan dan antikanker adalah tanaman keji beling (Strobilanthes crispa). Penelitian (Adibi et al., 2017) melaporkan bahwa ekstrak etanol daun keji beling memiliki aktivitas antioksidan dengan nilai IC $_{50}$ sebesar 102,85 ppm. Sehingga untuk itu perlu dilakukan pengujian toksisitas secara in vitro (metode BSLT) sebelum dilakukan terhadap sel kanker manusia. Tujuan penelitian ini adalah untuk mengetahui senyawa kimia dalam ekstrak etilasetat yang mempunyai daya toksisitas berdasarkan metode brine shrimp lethality test (BSLT).

\section{Metode Pendahuluan II.1 Alat dan Bahan}

Alat yang digunakan adalah Rotary vacuum evaporator (Stuart RE3022C), hotplate (Thermo Scientific CIMAREC), water bath (Memmert), thermometer, ultrasonic cleaner (Branson $\left.{ }^{\circledR} 1510\right)$, spektrofotometer UV-VIS (Hitachi U-3900H), oven (Elos), desikator, cawan porselin, lempeng silika gel $\mathrm{GF}_{254}$, bejana kromatografi, kromatografi kolom, statif, lampu TL, aerator, spektrofotometer Fourier Transform Infra Red, GC-MS, dan seperangkat alat gelas.

(c) (i) (D) Copyright (C) 2020 Jurnal Fitofarmaka Indonesia. This is an open-access article distributed under (c) ${ }_{\text {BY }}$ SA the terms of the Creative Commons Attribution-ShareAlike 4.0 International License 
Bahan yang digunakan dalam penelitian ini adalah daun keji beling (Strobilanthes crispa (L.) Blume) yang dikoleksi dari daerah Bogor, etanol $96 \%$, akuades, air laut, kertas saring, $\mathrm{HCl}$ pekat, pereaksi Wagner, pereaksi Mayer, pereaksi Dragendorff, metanol p.a, etil asetat pro analisis, magnesium, $\mathrm{FeCl}_{3}$, metanol, $n$-heksana, etil asetat, serium sulfat, larva Artemia salina, cellite, $\mathrm{KBr}$, silika gel 60 (70-230 Mesh), alumunium foil.

\section{II.2 Prosedur penelitian}

II.2.1 Determinasi Sampel

Daun keji beling yang diteliti terlebih dahulu dideterminasi di Herbarium Bogoriense, Pusat Penelitian Biologi - LIPI Jl. Raya Bogor Km 46, Cibinong untuk memastikan kebenaran dan keaslian dari tanaman yang digunakan.

\section{II.2.2 Pembuatan Simplisia}

Sebanyak $\pm 4 \mathrm{~kg}$ sampel disortasi basah dicuci dengan air mengalir, ditiriskan, dan sampel dirajang tipis-tipis, dikeringkan dengan cara diangin-anginkan (tidak di bawah sinar matahari langsung). Setelah kering sampel dihaluskan menggunakan blender dan diayak menggunakan saringan berukuran 40 mesh.

\section{II.2.3 Penentuan Kadar Air (AOAC, 2006)}

Penentuan kadar air dilakukan menurut metode Association of Official Analytical Chemist (Flowers et al., 2006).

\section{II.2.4 Ekstraksi}

Simplisia daun keji beling sebanyak 400 gram dimaserasi dengan pelarut etanol $96 \%$ selama 24 jam, terlindung dari cahaya sambil sesekali diaduk, dan dilakukan 6 kali pengulangan. Filtrat yang diperoleh dipekatkan menggunakan rotary vacuum evaporator pada suhu $50^{\circ} \mathrm{C}$ sampai diperoleh ekstrak kental etanol dan dihitung $\%$ rendemennya.

\section{II.2.5 Partisi Ekstrak Etanol 96\%}

Ekstrak etanol 96\% dilarutkan dengan 100 $\mathrm{ml}$ air dan dimasukkan ke dalam corong pisah kemudian tambahkan etil asetat sebanyak $100 \mathrm{ml}$ dipartisi, kocok dan diamkan sampai terjadi pemisahan antara lapisan etil asetat dan lapisan air, kemudian lapisan etil asetat ditampung. Hal ini dilakukan sampai lapisan etil asetat tidak berwarna (3 kali pengulangan). Lapisan air yang terbentuk ditampung dan dipekatkan di atas penangas air hingga kental (fraksi air). Lapisan etil asetat yang sudah ditampung kemudian diuapkan menggunakan rotary vacuum evaporator hingga kental (fraksi etil asetat).

\section{II.2.6 Skrining Fitokimia \\ Skrining fitokimia untuk golongan senyawa seperti alkaloid, flavonoid, saponin,}

terpenoid, steroid, tannin dan fenolik dilakukan berdasarkan metode metode (Buckley, 1966).

\section{II.2.7 Uji Aktivitas Sitotoksik DenganMetode BSLT (Brine Shrimp Lethality Test) \\ Uji aktivitas sitotoksik mengunakan menggunakan larva udang (Artemia salina) berdasarkan metode (Meyer, Ferrigni and Putnam, 1982) yang telah dimodifikasi.}

\section{II.2.8 Fraksinasi dengan Kromatografi Kolom}

Faksi etilasetat (10 gr) dimurnikan dengan menggunakan kromatografi Kolom $\left(\mathrm{SiO}_{2} ; n\right.$-heksanetilasetat $=20: 1 \sim 1: 1)$, dan kromatografi KLT preparative $\left(\mathrm{SiO}_{2} ; n\right.$-heksan-etilasetat $\left.=10: 1\right)$ dan menghasilkan isolat murni yang berbentuk cairan minyak. Skema kerja ekstraksi, isolasi senyawa kimia dari ekstrak etilasetat daun keji beling dapat dilihat pada Gambar 1.

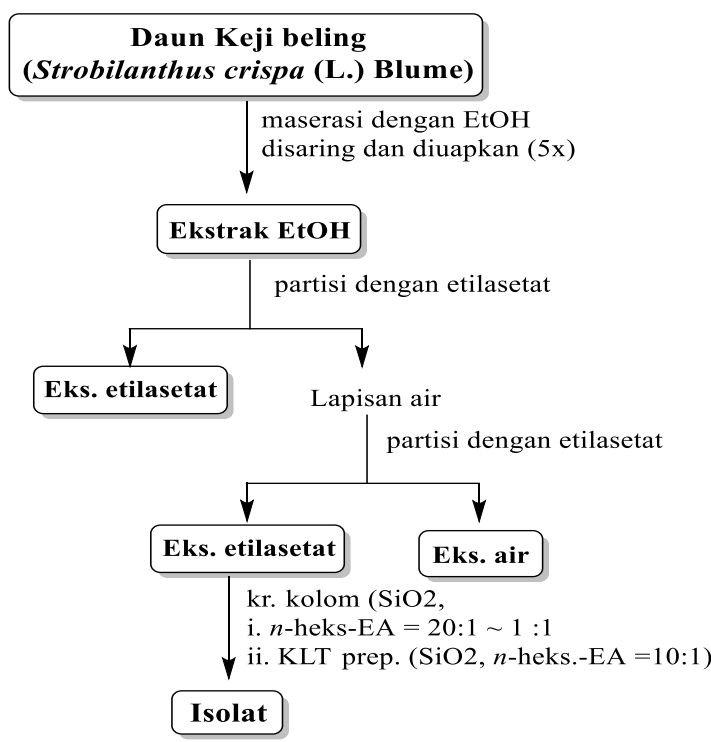

Gambar 1. Skema kerja ekstraksi, isolasi senyawa monoterpen dari ekstrak etril asetat keji beling (Strobilanthus crispa)

\section{Hasil dan Pembahasan}

III.1 Pembuatan Simplisia

Penetapan kadar air dilakukan untuk mengetahui kandungan air pada simplisia. Kadar air yang berlebih pada simplisia dapat menyebabkan pertumbuhan mikroba, jamur, reaksi enzimatis atau proses hidrolisis yang dapat menyebabkan perubahan kandungan kimia yang ada dalam bahan menjadi produk lain yang mungkin tidak lagi memiliki efek farmakologi seperti senyawa aslinya. Prosentasi penyusutan diperoleh 23,58 dan kadar air keji beling $4 \%$ (Tabel 1). Hasil kadar air ini memenuhi yang dipersyaratkan pada simplisia yaitu $\leq 10 \%$. 
Tabel 1. Peyusutan dan kadar air keji beling

\begin{tabular}{lllll}
\hline Sampel & $\begin{array}{l}\text { Berat Simplisia } \\
\text { Basah }(\mathbf{K g})\end{array}$ & $\begin{array}{l}\text { Berat Simplisia } \\
\text { Kering }(\mathbf{g})\end{array}$ & $\begin{array}{l}\text { Penyusutan } \\
(\boldsymbol{\%})\end{array}$ & Kadar Air $(\boldsymbol{\%})$ \\
\hline Daun Keji Beling & 3,9 & 920 & 23,58 & 4
\end{tabular}

\section{III.2 Pembuatan Ekstrak}

Rendemen ekstrak hasil ekstraksi dengan etilasetat keji beling diperoleh 1,42\% (Tabel 2). Ditinjau dari segi waktu pada metode maserasi, untuk memperoleh zat aktif yang lebih banyak dibutuhkan waktu dan proses yang lama karena ekstraksi ini tidak menggunakan bantuan panas (Wijaya, Novitasari and Jubaidah, 2018).

Tabel 2. Rendemen ekstrak etilasetat keji beling

\begin{tabular}{lllll}
\hline Sampel & $\begin{array}{l}\text { Berat Ekstrak } \\
\text { EtOH 95\% }(\mathbf{g})\end{array}$ & $\begin{array}{l}\text { Rendemen } \\
(\boldsymbol{\%})\end{array}$ & $\begin{array}{l}\text { Berat ekstrak } \\
\text { Etilasetat }(\mathbf{g})\end{array}$ & $\begin{array}{l}\text { Rendemen } \\
(\%)\end{array}$ \\
\hline $\begin{array}{l}\text { Daun Keji } \\
\text { Beling }\end{array}$ & 41,27 & 10,31 & 5,71 & 1,42 \\
\hline
\end{tabular}

Keterangan: Dihitung dari 400 gram berat kering simplisia

\section{III.3 Skrining Fitokimia}

Hasil uji skrining fitokimia untuk ekstrak etilasetat keji beling dapat dilihat pada Tabel 3.

Tabel 3. Hasil Uji Skrining Fitokimia

\begin{tabular}{llll}
\hline No. & Pengujian & Perubahan warna & Eks. Etilasetat \\
\hline 1. & Alkaloid & & \\
& a. Wagner & Endapan coklat kemerahan & + \\
& b. Mayer & Endapan putih/kuning & + \\
& c. Dragendorff & Endapan jingga coklat & + \\
2. & Flavonoid & Endapan merah kuning, jingga & + \\
3. & Saponin & Busa $1-10 \mathrm{~cm}$ & + \\
4. & Tanin & Hijau, hitam, merah ungu & + \\
5. & Terpenoid \& steroid & Cincin kecoklatan & + \\
\hline
\end{tabular}

Skrining fitokimia dilakukan untuk mengetahui kelompok senyawa kimia dalam tumbuhan yang mungkin dapat diperkirakan sebagai senyawa bioaktif. Pendekatan secara skrining fitokimia pada hakikatnya adalah analisis secara kualitatif dari kandungan kimia yang terdapat $d$ idalam tumbuhan atau bagian tumbuhan (akar, batang, daun, bunga, dan biji) terutama kandungan metabolit sekunder yang merupakan senyawa bioaktif seperti alkaloid, antrakuinon, flavonoid, glokosida jantung, kumarin, saponin, tanin, polifenol dan minyak atsiri(Ghasemzadeh, Jaafar and Rahmat, 2015) (Koay et al., 2013).

Tabel 4. Hasil Uji Aktivitas Sitotoksik Fraksi Etil Asetat Daun Keji Beling

\begin{tabular}{llllll}
\hline No & $\begin{array}{l}\text { Konsentrasi } \\
(\mathbf{p p m})\end{array}$ & $\begin{array}{l}\text { Log }[\mathbf{C}] \\
(\mathbf{p p m})\end{array}$ & \% Mortalitas & Probit & $\begin{array}{l}\text { LC } \\
(\mathbf{p p m})\end{array}$ \\
\hline 1 & $0($ kontrol) & - & - & - & \\
2 & 10 & 1 & 22,2 & 4,23 & 73,11 \\
3 & 100 & 2 & 37,73 & 5,61 & \\
4 & 1000 & 3 & 66,66 & 5,41 & \\
\hline
\end{tabular}

Pada pengujian aktivitas sitotoksik untuk fraksi etil asetat daun keji beling diperoleh $\mathrm{LC}_{50}$ 73,11 ppm (Tabel 4). Hasil ini menunjukkan bahwa fraksi etil asetat daun keji beling mempunyai aktivitas sitotoksik yang sangat toksik karena hasil tersebut masuk dalam range $0-100$ ppm (Clarkson et al., 2004).

\section{III.4 Fraksinasi Kromatografi Kolom}

Sebanyak 5,71 gram fraksi etil asetat daun keji beling difraksinasi dengan kromatografi kolom. Fase diam yang digunakan adalah silika gel 60 mesh $(0,063 \mathrm{~mm}-0,200 \mathrm{~mm})$ dengan fase gerak $n$-heksan - etil asetat secara gradien mulai dari 20:1 sampai 1:1. Fraksi dengan pola kromatogram yang sama digabung sehingga diperoleh 9 fraksi dan kromatogram KLT dapat dlihat pada Gambar 2. 


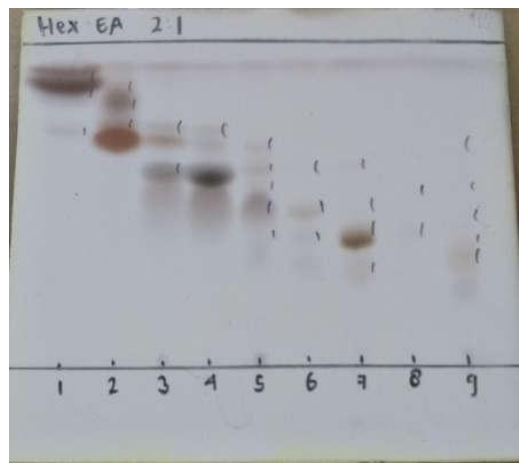

Gambar 2. Kromatogram KLT hasil kr. Kolom (Fr.1 fr. 9) Eluen : $n$-heksan-etilasetat $=2: 1$; spray : $\mathrm{CeSO}_{4} / \mathrm{H}_{2} \mathrm{SO}_{4}$

III.5 Uji Aktivitas Sitotoksik Fraksi Hasil Kromatografi Kolom

Hasil uji aktivitas sitotoksik menunjukkan bahwa fraksi-2, 4, 7, dan 8 memiliki nilai $\mathrm{LC}_{50}$ $39,81 \mathrm{ppm}, 85,11 \mathrm{ppm}, 66,06 \mathrm{ppm}, 81,28 \mathrm{ppm}$
(Gambar 3). Hasil ini menunjukkan bahwa fraksifraksi tersebut mempunyai aktivitas sitotoksik yang sangat toksik karena hasil tersebut masuk dalam range 0-100 ppm (Clarkson et al., 2004).

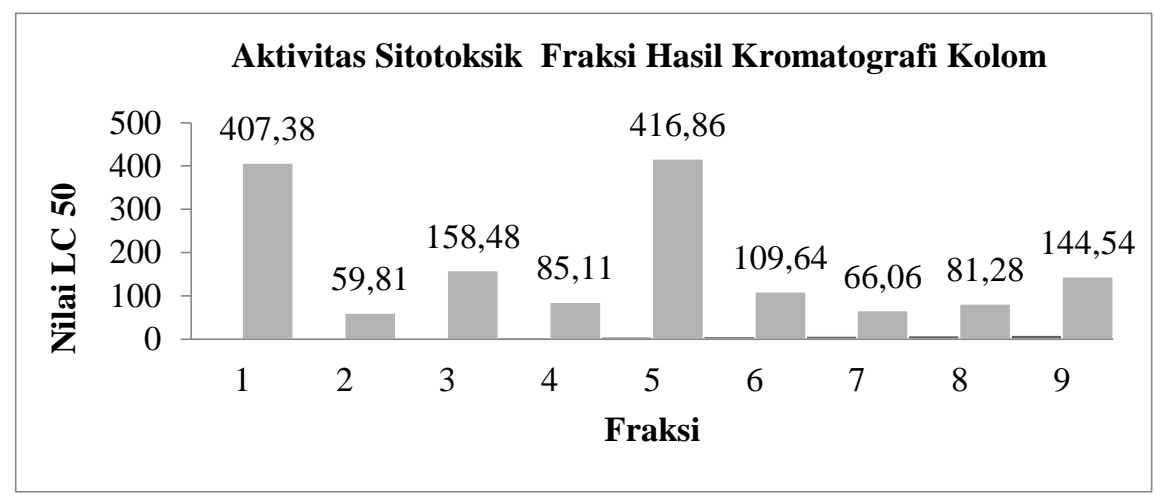

Gambar 3. Diagram batang hasil uji aktivitas sitotoksi fraksi etilasetat (fr.1 fr. 9)

Hasil uji aktivitas sitotoksik yang dipilih adalah fraksi 7 (66,06 ppm) untuk dilakukan isolasi dan diidentifikasi kandungan senyawa kimia karena, fraksi 7 memiliki pola kromatogram yang baik untuk dilakukan isolasi, disamping fraksi-2 (59,81 ppm) yang jumlahnya sedikt. Pemurnian senyawa fraksi 7 dilakukan dengan KLT preparatif $\left(\mathrm{SiO}_{2} ; n\right.$-heksanetilasetat $=10: 1$, memberikan isolat murni $\mathrm{X}$ yang berbentuk minyak.

\section{III.6 Identifikasi Senyawa}

\section{III.6.1 Spektrofotometer FTIR}

Hasil analisis spektrofotometer FTIR menunjukkan bahwa senyawa $\mathrm{X}$ memiliki gugus alkana $(\mathrm{CH})$ pada bilangan gelombang 2926, 798 $\mathrm{cm}^{-1}$, gugus alkena $(\mathrm{C}=\mathrm{C})$ pada $1641 \mathrm{~cm}^{1}$.

\section{III.6.2 Analisis Gas Chromatography-Mass Spectra (GC-MS)}

Pada kromatogram isolat $\mathrm{X}$ masih mempunyai senyawa impurities, yang disebabkan karena masih belum murni sehingga pada kromatogram terdeteksi beberapa peak (puncak) senyawa kimia dengan ketinggian yang berbedabeda. Hasil analisa kromatogram GC-MS pada Gambar 4 memberikan peak yang tinggi dan terdapat pada waktu retensi (Rt 7,75 menit) mempunyai kuantitas atau kadar yang paling besar yang diduga merupakan senyawa kimia utama yang terdapat di dalam isolat $\mathrm{X}$ dengan persen kemiripan (Qual) menurut database library sebesar 97\% (Gambar 5), dan diprediksi sebagai senyawa Dlimonen (Gambar 6). 


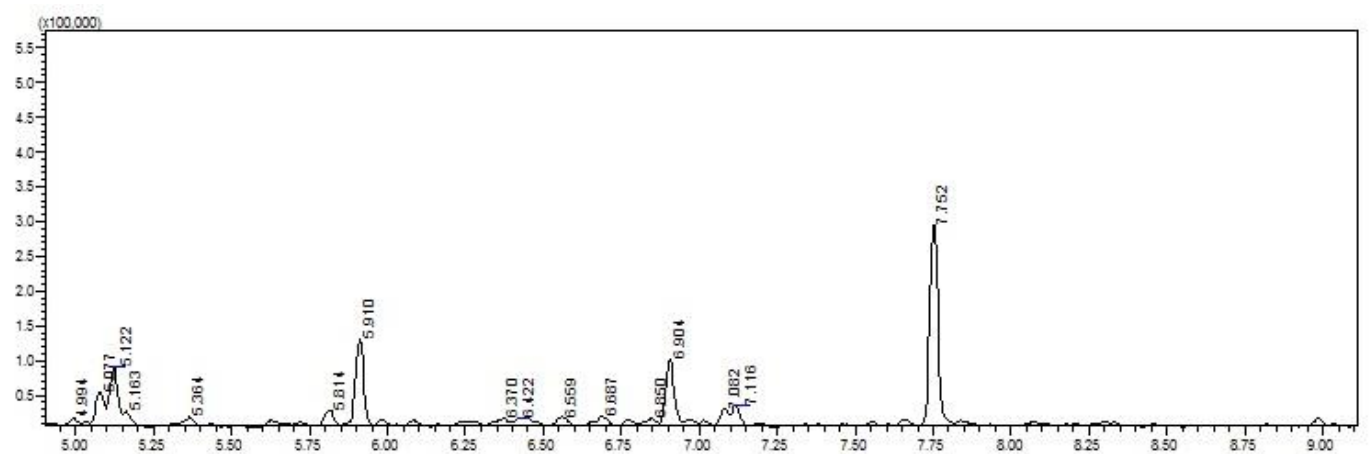

Gambar 4. Kromatogram kromatografi gas untuk isolat $\mathrm{X}$

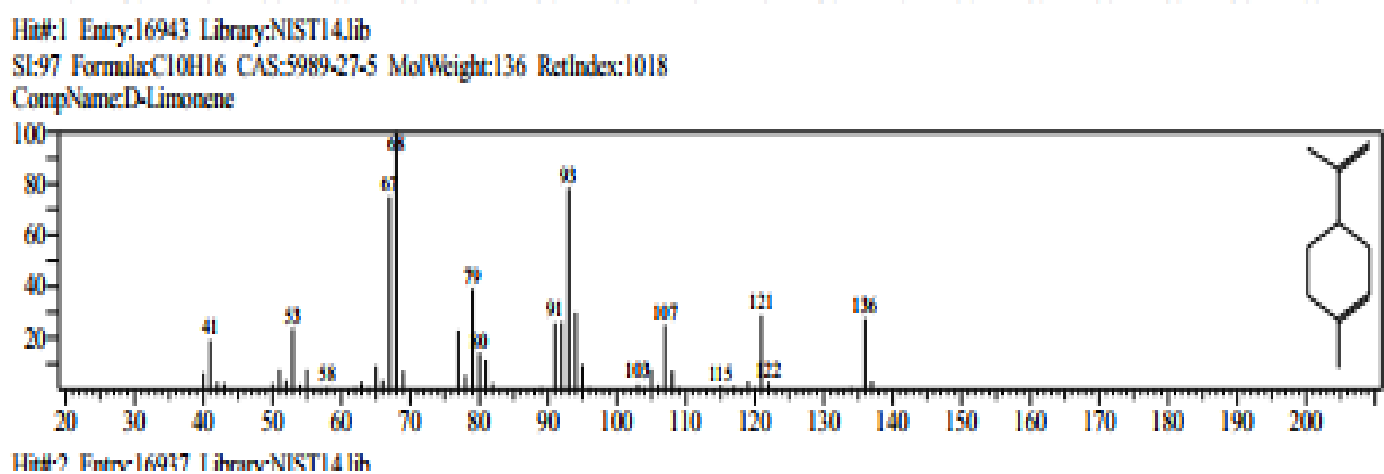

Gambar 5. Analisis fragmentasi untuk senyawa D-limonen pada GC-MS

Jadi berdasarkan hasil analisis GC-MS dan data spektra IR bahwa senyawa $X$ yang memiliki aktivitas sitotoksik dalam fraksi etil asetat daun keji beling adalah minyak atsiri golongan monoterpen Dlimonen (Gambar 6).<smiles>C=C(C)C1CC=C(C)CC1</smiles>

Gambar 6. Struktur kimia D-limonen

\section{Kesimpulan}

Salah satu senyawa kimia mono-terpen Dlimonen telah berhasil diisolasi dan diidentifikasi dari daun keji beling [(Strobilanthus crispa (L.) Blume] yang mempunyai daya toksik sebesar 73,11 ppm.

\section{Daftar Pustaka}

Adibi, S. et al. (2017) 'Induksi Tunas Keji Beling (Strobilanthes crispus L) Dengan Penambahan Kombinasi Naphtalen Acetic Acid (NAA) Dan 6-benzyl Amino Purin (BAP) Dalam Medium Cair'.

Buckley, J. P. (1966) 'Pharmaceutical sciences (Np)', Science, 151(3712), pp. 874-875. doi: $10.1126 /$ science.151.3712.874.

Clarkson, C. et al. (2004) 'In vitro antiplasmodial activity of medicinal plants native to or naturalised in South Africa', Journal of Ethnopharmacology, 92(2-3), pp. 177-
191. doi: 10.1016/j.jep.2004.02.011.

Dali, A. et al. (2017) 'Uji Aktivitas Antioksidan Ekstrak Metanol Daun Pecah Beling (Strobilanthes crispus)', Al-Kimia, 5(2), pp. 145-153.

Flowers, R. et al. (2006) 'Best Practices in Microbiological Methodology.', Aoac International, 12, p. 201.

Ghasemzadeh, A., Jaafar, H. Z. E. and Rahmat, A. (2015) 'Phytochemical constituents and biological activities of different extracts of Strobilanthes crispus (L.) Bremek leaves grown in different locations of Malaysia', BMC Complementary and Alternative Medicine. BMC Complementary and Alternative Medicine, 15(1), pp. 1-10. doi: 10.1186/s12906-015-0873-3.

Koay, Y. C. et al. (2013) 'Chemical constituents and biological activities of strobilanthes crispus L', Records of Natural Products, 7(1), pp. 59-64.

Koh, R. Y. et al. (2017) 'Anticancer mechanisms of Strobilanthes crispa Blume hexane extract on liver and breast cancer cell lines', Oncology Letters, 14(4), pp. 4957-4964. doi: 10.3892/ol.2017.6821.

Meyer, B. N., Ferrigni, N. R. and Putnam, J. E. (1982) 'Brine shrimp: A convenient general bioassay for active plant constituents', Planta Medica, 45(1), pp. 31-34. doi: 10.1055/s-2007-971236.

Nurraihana, H. and Norfarizan-Hanoon, N. A. (2013) 'Phytochemistry, pharmacology 
and toxicology properties of Strobilanthes crispus', International Food Research Journal, 20(5), pp. 2045-2056.

R. Hamidi, M., Jovanova, B. and Kadifkova Panovska, T. (2014) 'Toxicological evaluation of the plant products using Brine Shrimp (Artemia salina L.) model', Macedonian Pharmaceutical Bulletin, 60(01), pp. 9-18. doi: 10.33320/maced.pharm.bull.2014.60.01.00 2.

Rahmat, A. et al. (2006) 'Anticarcinogenic Properties of Strobilanthes crispus Extracts and its Compounds in vitro', pp. 47-49.

Setyawan, B. et al. (2016) 'Pembuktian Ekstrak Daun Kejibeling Dalam Meningkatkan Sistem Imun Info Artikel Verification Of Kejibeling Leaf Extract In Improving The Immune System', Kesehatan Masyarakat, 11(2).

Wijaya, H., Novitasari and Jubaidah, S. (2018) 'Perbandingan Metode Ekstraksi Terhadap Rendemen Ekstrak Daun Rambut Laut (Sonneratia caseolaris L. Engl)', Jurnal Ilmiah Manuntung, 4(1), pp. 79-83. 